PONTIFÍCIA UNIVERSIDADE CATÓLICA DO RIO DE JANEIRO

\title{
Um Estudo Sobre o Processo de Fusões e Aquisições no Mercado Brasileiro
}

\author{
Hudson de Carvalho Neto \\ Trabalho de Conclusão de Curso
}

CENTRO DE CIÊNCIAS SOCIAIS - CCS

DePARTAMENTO de AdMINISTRAÇÃo

Graduação em Administração de Empresas 


\section{Um Estudo Sobre o Processo de Fusões e Aquisições no Mercado Brasileiro}

Trabalho de Conclusão de Curso

Trabalho de Conclusão de Curso, apresentado ao programa de graduação em Administração da PUC-Rio como requisito parcial para a obtenção do título de graduação em Administração.

Orientadora: Graziela Fortunato

Rio de Janeiro,

Dezembro de 2016. 
De Carvalho Neto, Hudson.

\section{Um Estudo Sobre o Processo de Fusões e Aquisições no Mercado Brasileiro}

Rio de Janeiro, 2016. 23 páginas.

Trabalho de Conclusão de Curso - Departamento de Administração.

Pontifícia Universidade Católica do Rio de Janeiro.

\section{Resumo}

Esse trabalho objetiva os processos de fusão e aquisição que ocorreram entre os anos de 2010 e 2011 de 3 empresas de diferentes setores do mercado brasileiro, através de índices financeiros a fim de determinar se o desempenho econômico-financeiro foi melhor ou pior como consequência do processo. $O$ estudo foi empreendido por meio da comparação dos valores médios de índices no triênio anterior e no posterior à união das empresas. Identificou-se uma melhora na situação financeira econômica tal como operacionais e gerenciais.

Palavras-chave: Fusão e Aquisição, Indicadores Financeiros, Mercado Brasileiro, Desempenho Econômico Financeiro. 
De Carvalho Neto, Hudson.

\title{
A Study of Mergers \& Acquisition Processes in the Brazilian Market.
}

Rio de Janeiro, 2016. 23 pages.

Final Paper - Business Administration Department.

Pontifícia Universidade Católica do Rio de Janeiro.

\begin{abstract}
This study aims at the merger and acquisition processes that occurred between 2010 and 2011 of 3 companies from different sectors of the Brazilian market, through financial indicators, in order to determine if economic-financial performance was better or worse as a consequence of the process. The study was carried out by comparing the main financial indicators in the previous triennium and in the post-union period. We identified an improvement in the economic financial situation as well as operational and managing improvements.
\end{abstract}

Key-words: Mergers \& Acquisitions, Brazilian Market, Financial Indicators, Financial Performance. 
Sumário

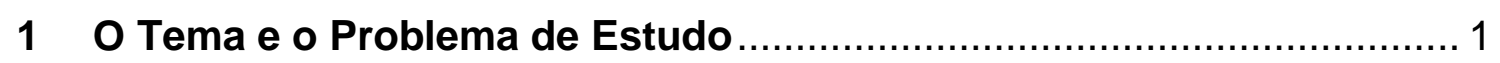

1.1 Introdução ao Tema e Problema de Estudo.................................... 1

1.2 Objetivo Final do Tema e Problema de Estudo ……....................... 1

1.3 Objetivos Intermediários do Tema e Problema de Estudo ….......... 2

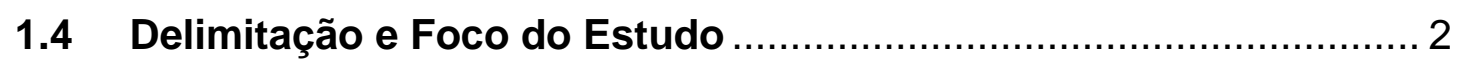

1.5 Justificativa e Relevância do Estudo ………............................. 2

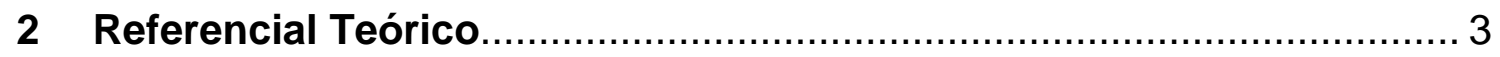

2.1 Processo de Fusões e Aquisições ………................................... 3

2.2 O Referencial Teórico de Camargos e Medeiros (2005)................. 4

2.3 Breve Análise das Fusões da Braskem, do Itaú Unibanco e BRF .. 5

3 Metodologia: Amostra; Coleta de Dados ………................................. 5

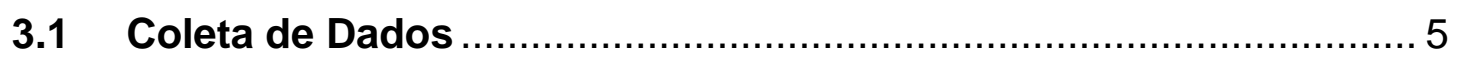

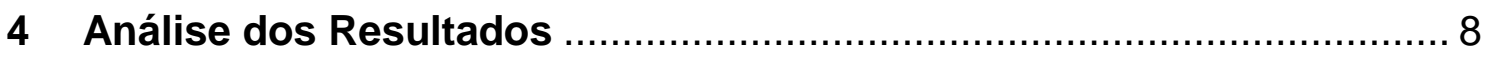

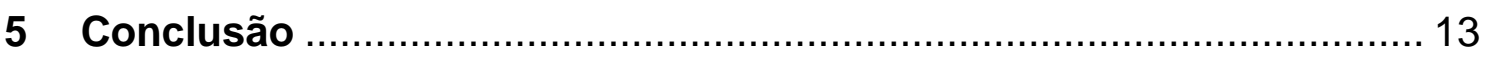

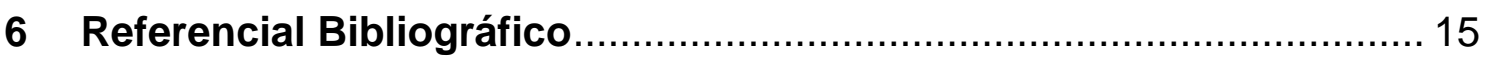


Tabelas

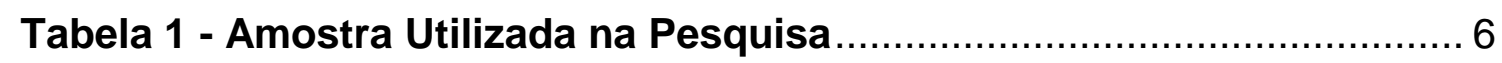

Tabela 2 - Indicadores Econômico-Financeiros Utilizados …...................... 7

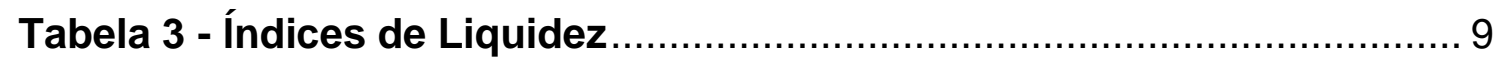

Tabela 4 - Índices de Endividamento.................................................... 10

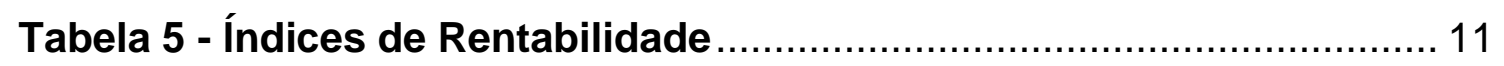

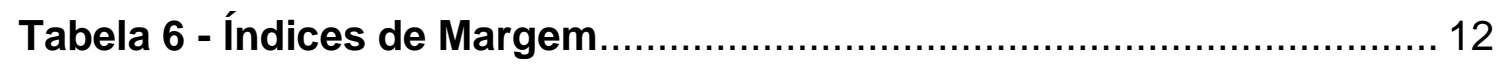




\section{O Tema e o Problema de Estudo}

\subsection{Introdução ao Tema e Problema de Estudo}

O termo aquisição pode ser definido como um processo em que uma empresa, seja de capital aberto ou fechado, detém o controle acionário de uma outra empresa, determinando o desaparecimento legal da empresa comprada, implicando em alto grau de investimento e de controle, além de um processo de integração mais complexo. Dessa forma, trata-se da compra de uma empresa por outra, na qual somente uma delas manterá sua identidade. (Santos, 2007).

No Brasil, nos anos 90s, teve sua maior onda de fusões e aquisições (F\&A) em sua história. As fusões e aquisições brasileiras cresceram, devido principalmente ao processo de privatização ocorrido no período. Para a década seguinte, devido a diversas crises econômicas e a grandes números de regulamentações impostas no país, os padrões de F\&A no mercado brasileiro foram alterados.

Entretanto, é valido lembrar que foi durante essa década que o Brasil atingiu seu maior sucesso econômico, com a entrada em massa de diversas empresas estrangeiras e grandes investimentos vindos de outros países. Portanto, por muitas vezes as próprias empresas nacionais se unificaram ou se adquiriram para tentar concorrer com seus competidores internacionais que ingressaram no país nessa época.

\subsection{Objetivo Final do Tema e Problema de Estudo}

O objetivo principal do estudo é, abordando o cenário de F\&A brasileiro, analisar o desempenho econômico-financeiro de 3 empresas de capital aberto (Braskem, BRF e Itaú Unibanco) que passaram por processos de fusão e aquisição entre os anos de 2010 e de 2011 e determinar se os resultados desse processo, em 2016, foram positivos ou negativos. 


\subsection{Objetivos Intermediários do Tema e Problema de Estudo}

Para alcançar o objetivo, foram escolhidos 3 casos de fusões e/ou aquisições das empresas no mercado brasileiro entre os anos de 2010 e 2011 . As entidades escolhidas são Braskem, BRF e Itaú Unibanco. As empresas estudadas estão inseridas em diferentes setores, sendo eles: química, alimentícia e financeiro, respectivamente.

Apesar de ser um estudo voltado para uma análise financeira, também é imprescindível entender o processo de aquisições e fusões no mercado, para assim compreender o motivo pelo qual as empresas optam por essas opções. Este estudo teve como referencial teórico o trabalho de Camargos e Barbosa (2005).

\subsection{Delimitação e Foco do Estudo}

Para tal, o estudo se delimitará apenas na análise financeira de 3 empresas nacionais de capital aberto na Bovespa (pela acessibilidade às informações financeiras desses grupos) nos segmentos alimentício, químico e financeiro, durante os anos de 2010 e de 2011.

Além disso, serão utilizados os índices financeiros específicos para poder determinar o desempenho das companhias ao longo dos anos após a fusão ou aquisição. Dentro dos índices estão inclusos os de rentabilidade, margens, endividamento e de liquidez.

\subsection{Justificativa e Relevância do Estudo}

O estudo em questão é relevante devido a diversos fatores ligados a diferentes elos do mercado brasileiro, bem como àqueles que se dedicam a pensar na economia do país como um todo.

Contribuições de cunho prático podem se dar a partir do presente estudo. Os mapeamentos, análises financeiras, referências bibliográficas e indicações feitas podem servir de base para aplicação de elaboração de estratégias de compra e venda de ativos financeiros, bem como servir como exemplo para futuros estudos sobre os processos de F\&A no mercado brasileiro. 
Finalmente, esse estudo busca atualizar o artigo feito por Camargos e Barbosa (2005), com informações recentes de mercado e de processo de F\&A no mercado brasileiro.

\section{Referencial Teórico}

\subsection{Processo de Fusões e Aquisições}

Conforme descrito por Medeiros (2009), o termo aquisição pode ser definido como um processo em que uma empresa, seja de capital aberto ou fechado, detém o controle acionário de uma outra empresa, determinando o desaparecimento legal da empresa comprada, implicando em alto grau de investimento e de controle, além de um processo de integração mais complexo. Dessa forma, trata-se da compra de uma empresa por outra, na qual somente uma delas manterá sua identidade.

Fusões e aquisições (F\&A) é um termo geral que se refere à consolidação de empresas ou ativos. O conceito de fusão significa uma combinação de duas empresas para formar uma nova empresa, enquanto que uma aquisição é a compra de uma empresa por outra em que nenhuma nova empresa é formada.

Numa fusão, os conselhos de administração de duas empresas aprovam a combinação e buscam a aprovação dos acionistas de cada entidade. Após a fusão, as empresas deixam de existir e passam a fazer parte da sociedade incorporante.

Em uma aquisição, a empresa adquirente obtém a participação majoritária nas empresas adquiridas, o que não altera o seu nome ou a estrutura legal.

As principais vantagens para as organizações optarem por realizar uma fusão ou aquisição são:

- Sinergia, que é a ideia de que através da combinação de atividades de negócios, o desempenho vai aumentar e os custos serão reduzidos. Essencialmente, uma empresa vai tentar fundir com outra empresa que tem pontos fortes e fracos complementares.

- Diversificação: Uma empresa que se funde para diversificar seus negócios pode adquirir outra empresa em uma indústria aparentemente não relacionados, a fim de reduzir o impacto do desempenho de uma indústria em particular sobre 
a sua rentabilidade. As empresas que pretendem melhorar o foco muitas vezes fundem-se com empresas que têm maior penetração de mercado em uma áreachave das operações.

- Crescimento: Fusões podem dar às empresas adquirentes uma oportunidade de aumentar a quota de mercado sem ter que realmente ganhá-lo fazendo o trabalho por si só - em vez disso, eles compram os negócios de um concorrente por um preço. Normalmente, estes são chamados de concentrações horizontais.

- Aumentar o Supply-Chain. Ao comprar um de seus fornecedores ou um dos distribuidores, uma empresa pode eliminar um nível de custos. Se uma empresa compra um de seus fornecedores, é capaz de economizar nas margens que o fornecedor foi previamente adicionando aos seus custos; isso é conhecido como uma fusão vertical. Se uma empresa compra para um distribuidor, que pode ser capaz de distribuir os seus produtos a um custo mais baixo.

- Eliminar a concorrência: Muitas fusões permitem que o adquirente elimine a concorrência futuro e ganhe uma maior quota de mercado.

\subsection{O Referencial Teórico de Camargos e Medeiros (2005)}

Camargos e Barbosa (2005), referencial teórico deste trabalho, avaliam se houve sinergias positivas em uma amostra de organizações que passaram por um processo de fusão e aquisição entre os anos de 1995 e 1999, por meio do cálculo de índices financeiros específicos. O prazo escolhido foi de sete anos, sendo os primeiros três anos antecedentes a fusão, o ano da fusão e os três anos após o processo.

Os autores se aproveitaram de uma série de fenômenos das fusões e aquisições ocorridas no Brasil nos anos 90, e dado ao cenário econômico positivo a época. Foi nesse tempo que o Plano Real que acabará de ser imposto, e houvera uma grande onda de privatizações e entrada de capital estrangeiro no país.

O trabalho conclui que, mesmo em situação econômica favorável, houve uma piora na situação financeira das empresas, e o contrário ocorreu na situação econômica o que gerou melhoras nas margens operacionais e gerencias. 


\subsection{Breve Análise das Fusões da Braskem, do Itaú Unibanco e BRF}

Foram escolhidos 3 casos reais de fusão e aquisição no mercado brasileiro entre os anos de 2010 e 2011. As empresas escolhidas foram o Itaú Unibanco, BRF e Braskem.

Em 2010 a empresa Quattor, a segunda maior empresa petroquímica do Brasil, foi adquirida pela Braskem da Unipar pelo valor de $\mathrm{R} \$ 870$ milhões. A aquisição foi uma das maiores do setor no país, e colocou a Braskem entre as principais da indústria química do Brasil.

Em 2008, a fusão entre os bancos Itaú e Unibanco foi anunciada e a maior holding de instituição financeira do país foi criada (concluída em 2010). Juntas, as duas instituições tinham em setembro de 2008 ativos de 575,1 bilhões de reais, contra 403,5 bilhões do Banco do Brasil, e R $\$ 348,4$ bilhões do Bradesco, um patrimônio líquido de cerca de 51,7 bilhões de reais e uma carteira de crédito combinada de 225,3 bilhões de reais. O lucro líquido somado dos dois bancos de janeiro a setembro deste ano foi de 8,1 bilhões de reais. Com a fusão, a marca Unibanco foi excluída, permanecendo apenas a do Itaú. O processo, na época, foi avaliado em mais de $\mathrm{R} \$ 1$ bilhão.

Em 2009, o processo de fusão da Perdigão S.A. da Sadia S.A. foi anunciada e em 2011, após a aprovação do CADE, a BRF S.A. (Brasil Foods S.A.) foi criada. Com isso o grupo tornou-se o maior player do mercado alimentício do Brasil, e um dos principais players no mundo. O conglomerado atua nos segmentos de carnes, alimentos processados, margarinas, massas, pizzas e vegetais congelados.

\section{Metodologia: Amostra; Coleta de Dados}

\subsection{Coleta de Dados}

Esse trabalho tem como objetivo analisar o desempenho econômicofinanceiro, através de indicadores de três companhias, BRF, Braskem e Itaú Unibanco que passaram por um processo de aquisição ou fusão entre 2010 e 
2011 no mercado brasileiro. Tratam-se de empresas de sociedade anônima de capital aberto, negociadas na Bolsa de Valores de São Paulo (BOVESPA), facilitando a obtenção de seus dados financeiros.

A lista de empresas com os respectivos anos das fusões foi obtida através do site da Exame em 2010, enquanto que os demonstrativos financeiros (balanço patrimonial e demonstrações do resultado do exercício) foram adquiridos pelo próprio site das companhias, na área de relação com investidores.

O período escolhido para a análise desse estudo se deve pelo fato de que o país estava vivendo uma situação econômica estável, com uma taxa de juros (SELIC) e índice de inflação (IPCA) menores que os atuais.

A Tabela 1 apresenta informações das empresas como 0 ano da fusão/aquisição, setor de atuação e o adquirente.

Tabela 1 - Amostra Utilizada na Pesquisa

\begin{tabular}{|l|l|l|l|l|l|}
\hline & \multicolumn{1}{|c|}{ Empresa } & \multicolumn{1}{c|}{ Setor } & \multicolumn{1}{c|}{ Adquirente } & \multicolumn{1}{c|}{ Ano } & \multicolumn{1}{c|}{ Tipo } \\
\hline 1 & Unibanco & Financeiro & Itaú & 2010 & Fusão \\
\hline 2 & Sadia & Alimentício & BRF & 2011 & Fusão \\
\hline 3 & Quattor & Químico & Braskem & 2010 & Aquisição \\
\hline
\end{tabular}

Fonte: Elaborada pelo autor

A análise de desempenho econômico-financeiro das entidades envolvidas em processos de aquisições e fusões foi feita com as demonstrações financeiras consolidadas dos grupos, pela análise da evolução de índices financeiros, como índice de liquidez, endividamento, rentabilidade e de sinergias.

O período de análise foi de 7 anos, sendo os 3 anos antes do processo de fusão e aquisição (F\&A), o próprio ano da concretização dos processos e os 3 anos seguidos da finalização do processo de F\&A.

Os índices de liquidez são utilizados para medir a capacidade da empresa para pagar as suas obrigações de dívida e sua margem de segurança e incluem o índice de liquidez corrente e índice de liquidez geral (Assaf Neto, 2015).

Os índices de endividamento são utilizados para medir o nível de endividamento/capital próprio da empresa. Além disso, também são utilizados para calcular o nível de alavancagem da empresa. Os índices deste grupo mais 
comumente utilizados são endividamento geral, perfil da dívida e participação de capital em terceiros (Assaf Neto, 2015).

Os índices de rentabilidade são utilizados para medir a capacidade de geração de fundos, com valor de disponibilidade imediata, de cada unidade monetária investida no projeto. Os principais são o retorno sobre os ativos, retorno sobre o PL e lucro por ação. Além dos índices mencionados acima, outros índices de rentabilidade foram utilizados nesse estudo, mais especificamente a margem bruta e margem líquida (Assaf Neto, 2015).

Como o presente estudo tem como objetivo final a atualização do trabalho feito por Camargos e Barbosa (2005), os índices utilizados para realizar as devidas análises serão os mesmos, conforme descrito no Quadro1.

\section{Tabela 2 - Indicadores Econômico-Financeiros Utilizados}

\begin{tabular}{|c|c|c|c|}
\hline \multicolumn{4}{|c|}{ Índices de Liquidez } \\
\hline Indicadores & Cálculo & Indica & Interpretação \\
\hline $\begin{array}{l}\text { Liquidez Geral } \\
\text { (LG) }\end{array}$ & $L G=\frac{A C+A N C}{P C+P N C}$ & $\begin{array}{l}\text { A capacidade da empresa } \\
\text { de honrar seus } \\
\text { compromissos para com } \\
\text { terceiros seja de CP ou LP. }\end{array}$ & Quanto maior, melhor \\
\hline $\begin{array}{l}\text { Liquidez Corrente } \\
\text { (LC) }\end{array}$ & $L C=\frac{\text { Ativo Circulante }}{\text { Passivo Circulantel }}$ & $\begin{array}{l}\text { A capacidade da empresa } \\
\text { de pagar suas dívidas de } \\
\text { CP }\end{array}$ & Quanto maior, melhor \\
\hline \multicolumn{4}{|c|}{ Índices de Endividamento } \\
\hline Indicadores & Cálculo & Indica & Interpretação \\
\hline $\begin{array}{l}\text { Perfil da Dívida } \\
\text { (PD) }\end{array}$ & $P D=\frac{\text { Dívida Financeira CP }}{\text { Dívida Financeira Total }}$ & $\begin{array}{l}\text { Quanto da dívida financeira } \\
\text { total da empresa deverá ser } \\
\text { paga no CP. }\end{array}$ & Quanto menor, melhor \\
\hline $\begin{array}{l}\text { Grau de } \\
\text { Endividamento } \\
\text { Financeiro (GEF) }\end{array}$ & GEF $=\frac{\text { Dívida Financeira Total }}{\text { Ativo Total }}$ & $\begin{array}{l}\% \text { de capital de terceiros } \\
\text { que financiam os } \\
\text { investimentos da empresa. }\end{array}$ & Quanto menor, melhor \\
\hline $\begin{array}{l}\text { Participação de } \\
\text { Capitais de } \\
\text { Terceiros (PCT) }\end{array}$ & PCT $=\frac{\text { Dívida Financeira Total }}{\text { Patrimônio Líquido }}$ & $\begin{array}{l}\text { \% de recursos de terceiros } \\
\text { em relação aos recursos } \\
\text { próprios. }\end{array}$ & Quanto menor, melhor \\
\hline \multicolumn{4}{|c|}{ Índices de Rentabilidade } \\
\hline Indicadores & Cálculo & Indica & Interpretação \\
\hline $\begin{array}{l}\text { Retorno sobre o } \\
\text { Ativo (ROA) }\end{array}$ & $\mathrm{ROA}=\frac{\text { Lucro Líquido }}{\text { Ativo Total }} \times 100$ & $\begin{array}{l}\text { A medida do retorno } \\
\text { proporcionado pelos } \\
\text { investimentos totais nos } \\
\text { ativos da empresa. }\end{array}$ & Quanto maior, melhor \\
\hline $\begin{array}{l}\text { Retorno sobre o } \\
\text { PL (ROE) }\end{array}$ & $\mathrm{ROE}=\frac{\text { Lucro Líquido }}{\text { Patri. Líquido }} \times 100$ & $\begin{array}{l}\text { A medida do retorno } \\
\text { proporcionado pela empresa } \\
\text { em relação ao capital que } \\
\text { nela foi investido. }\end{array}$ & Quanto maior, melhor \\
\hline $\begin{array}{l}\text { Lucro por Ação } \\
\text { (LPA) }\end{array}$ & LPA $=\frac{\text { Lucro Líquido }}{\text { Ações Ordinárias }}$ & $\begin{array}{l}\text { Retorno para os acionistas } \\
\text { ordinários decorrente das } \\
\text { atividades da empresa. }\end{array}$ & Quanto maior, melhor \\
\hline \multicolumn{4}{|c|}{ İndices de Margens } \\
\hline Indicadores & Cálculo & Indica & Interpretação \\
\hline $\begin{array}{l}\text { Margem Bruta } \\
(\mathrm{MB})\end{array}$ & $\mathrm{MB}=\frac{\text { Lucro Bruto }}{\text { Receita Líquida }} \times 100$ & $\begin{array}{l}\text { Se as empresas } \\
\text { apresentaram economias de } \\
\text { escala com o maior porte e } \\
\text { poder de mercado que } \\
\text { passaram a ter com a fusão } \\
\text { / aquisição. }\end{array}$ & Quanto maior, melhor \\
\hline $\begin{array}{l}\text { Margem Líquida } \\
(\mathrm{ML})\end{array}$ & $\mathrm{ML}=\frac{\text { Lucro Líquido }}{\text { Receita Líquida }} \times 100$ & $\begin{array}{l}\text { Se as empresas } \\
\text { melhoraram sua eficiência } \\
\text { operacional, administrativa e } \\
\text { financeira. }\end{array}$ & Quanto maior, melhor \\
\hline
\end{tabular}




\begin{tabular}{|l|l|l|l|}
\hline & & $\begin{array}{l}\text { \% das despesas } \\
\text { administrativas e gerais } \\
\text { sobre a receita líquida. } \\
\text { Despesas } \\
\begin{array}{l}\text { Administrativas } \\
\text { Gerais (DAG) } \\
\text { redução das despesas } \\
\text { administrativas após a } \\
\text { união. }\end{array}\end{array}$ & Quanto maior, pior \\
\hline
\end{tabular}

Fonte: Camargos e Barbosa (2005)

Além dos índices mencionados acima, a equação para o cálculo de maneira agregada dos valores encontrados, pelo prazo de sete anos ( 3 anos antes, 1 ano da F\&A, e 3 anos posteriormente), será baseada na Equação 1 proposta no artigo escrito por Camargos e Barbosa (2005), conforme abaixo.

$$
\sum_{t=-3}^{-1} \frac{\left(\sum_{i=1}^{n} \operatorname{In} d_{X, t}\right)}{n} \Leftrightarrow \sum_{t=1}^{3} \frac{\left(\sum_{i=1}^{n} \operatorname{In} d_{X, t}\right)}{n}
$$

Os resultados obtidos para cada índice dos três anos anteriores serão comparados ao resultado achado nos três anos seguintes e será analisado se houve uma melhor ou uma piora financeira-econômica com a aquisição ou fusão, independente do setor.

\section{Análise dos Resultados}

Os resultados obtidos, através do cálculo dos índices de cada empresa estudada, serão dividos em quatro grupos, começando pelos índices de liquidez seguidos por índices de endividamento, rentabilidade, margem e finalmente 0 resultado obtido com a equação proposta.

As demonstrações financeiras foram obtidas através dos sites das empresas estudadas pela aba de relação com os investidores e os números são focados na operação consolidada das operações de cada grupo econômico nos anos indicados abaixo. 
Tabela 3 - Índices de Liquidez

\begin{tabular}{|c|c|c|c|c|c|c|c|c|c|c|c|c|}
\hline \multicolumn{13}{|c|}{ ÍNDICES DE LIQUIDEZ } \\
\hline \multirow{2}{*}{ ÍNDICE } & \multirow{2}{*}{ EMPRESA } & \multicolumn{8}{|c|}{ ANOS RELATIVOS } & \multicolumn{2}{|c|}{ MÉDIA } & \multirow{2}{*}{ VARIAÇÃO } \\
\hline & & 2007 & 2008 & 2009 & 2010 & 2011 & 2012 & 2013 & 2014 & ANTES & DEPOIS & \\
\hline \multirow{3}{*}{ LC } & Braskem & 1,11 & 1,02 & 0,93 & 1,04 & 1,12 & 0,99 & 1,10 & - & 1,02 & 1,07 & $4,88 \%$ \\
\hline & BRF & - & 1,94 & 1,78 & 1,76 & 1,39 & 1,55 & 1,57 & 1,83 & 1,83 & 1,65 & $-9,67 \%$ \\
\hline & Itaú Unibanco & 1,15 & 1,12 & 1,39 & 1,41 & 1,48 & 1,36 & 1,32 & - & 1,22 & 1,39 & $13,66 \%$ \\
\hline \multicolumn{2}{|c|}{ MÉDIA GERAL } & 1,13 & 1,36 & 1,37 & 1,40 & 1,33 & 1,30 & 1,33 & 1,83 & 1,36 & 1,37 & $0,98 \%$ \\
\hline \multirow{3}{*}{ LG } & Braskem & 0,60 & 0,58 & 0,55 & 0,42 & 0,42 & 0,52 & 0,47 & - & 0,58 & 0,47 & $-18,35 \%$ \\
\hline & BRF & - & 0,98 & 0,74 & 0,60 & 0,71 & 0,68 & 0,76 & 0,92 & 0,77 & 0,79 & $1,72 \%$ \\
\hline & Itaú Unibanco & 1,52 & 1,55 & 2,03 & 2,06 & 1,79 & 1,93 & 1,94 & - & 1,70 & 1,89 & $10,98 \%$ \\
\hline \multicolumn{2}{|c|}{ MÉDIA GERAL } & 1,06 & 1,04 & 1,11 & 1,03 & 0,97 & 1,04 & 1,06 & 0,92 & 1,02 & 1,05 & $3,09 \%$ \\
\hline
\end{tabular}

Fonte: Elaborada pelo autor

Com exceção da BRF (onde houve uma queda de 9,67\% em relação aos três anos que antecedem o processo de fusão), o índice de liquidez corrente obteve uma melhora após o processo de aquisição por parte da Braskem, com variação positiva de $4,88 \%$ e pela fusão do Itaú com o Unibanco, com uma variação positiva de $13,66 \%$ nos três anos após o anúncio do processo. A média geral do índice foi positiva em 0,98\%.

Já em relação ao índice de liquidez geral, a média geral da variação ficou em 3,09\%, apesar da forte queda do índice do grupo Braskem de 18,35\%. Entretanto, tanto a BRF quanto o Itaú Unibanco obtiveram resultados positivos de $1,72 \%$ e $10,98 \%$ respectivamente.

Desta forma observou-se que os índices de liquidez, na maioria dos casos, tiveram uma melhora nos três anos após o processo de F\&A em relação aos três anos que antecedem o processo. 
Tabela 4 - Índices de Endividamento

\begin{tabular}{|c|c|c|c|c|c|c|c|c|c|c|c|c|}
\hline \multicolumn{13}{|c|}{ ÍNDICES DE ENDIVIDAMENTO } \\
\hline \multirow{2}{*}{ ÍNDICE } & \multirow{2}{*}{ EMPRESA } & \multicolumn{8}{|c|}{ ANOS RELATIVOS } & \multicolumn{2}{|c|}{ MÉDIA } & \multirow{2}{*}{ VARIAÇÃO } \\
\hline & & 2007 & 2008 & 2009 & 2010 & 2011 & 2012 & 2013 & 2014 & ANTES & DEPOIS & \\
\hline \multirow{3}{*}{ PD } & Braskem & 0,14 & 0,19 & 0,20 & 0,10 & 0,09 & 0,10 & 0,07 & - & 0,18 & 0,09 & $-50,60 \%$ \\
\hline & BRF & - & 0,31 & 0,33 & 0,31 & 0,43 & 0,26 & 0,26 & 0,24 & 0,32 & 0,25 & $-20,00 \%$ \\
\hline & Itaú Unibanco & 0,65 & 0,66 & 0,42 & 0,46 & 0,51 & 0,52 & 0,50 & - & 0,58 & 0,51 & $-11,56 \%$ \\
\hline \multicolumn{2}{|c|}{ MÉDIA GERAL } & 0,40 & 0,39 & 0,32 & 0,29 & 0,34 & 0,29 & 0,28 & 0,24 & 0,36 & 0,28 & $-20,50 \%$ \\
\hline \multirow{3}{*}{ GEF } & Braskem & 0,05 & 0,09 & 0,08 & 0,03 & 0,03 & 0,04 & 0,03 & - & 0,07 & 0,03 & $-54,73 \%$ \\
\hline & BRF & - & 0,15 & 0,11 & 0,08 & 0,12 & 0,08 & 0,08 & 0,08 & 0,11 & 0,08 & $-29,41 \%$ \\
\hline & Itaú Unibanco & 0,07 & 0,08 & 0,02 & 0,03 & 0,03 & 0,03 & 0,03 & - & 0,06 & 0,03 & $-47,06 \%$ \\
\hline \multicolumn{2}{|c|}{ MÉDIA GERAL } & 0,06 & 0,11 & 0,07 & 0,05 & 0,06 & 0,05 & 0,05 & 0,08 & 0,08 & 0,05 & $-41,15 \%$ \\
\hline \multirow{3}{*}{ PCT } & Braskem & 1,30 & 1,76 & 1,87 & 1,17 & 1,52 & 2,02 & 2,47 & - & 1,64 & 2,00 & $21,78 \%$ \\
\hline & BRF & - & 0,82 & 0,32 & 0,27 & 0,38 & 0,48 & 0,46 & 0,32 & 0,47 & 0,42 & $-10,64 \%$ \\
\hline & Itaú Unibanco & 1,79 & 2,65 & 0,64 & 0,73 & 0,77 & 0,79 & 0,92 & - & 1,69 & 0,83 & $-51,18 \%$ \\
\hline \multicolumn{2}{|c|}{ MÉDIA GERAL } & 1,55 & 1,74 & 0,94 & 0,72 & 0,89 & 1,10 & 1,28 & 0,32 & 1,27 & 1,08 & $-14,68 \%$ \\
\hline
\end{tabular}

Fonte: Elaborada pelo autor

O índice perfil da dívida das empresas estudas apresentou uma queda geral em relação aos três anos que antecederam o processo de aquisição ou de fusão. Isso significa que o a dívida de curto prazo em relação a dívida total foi reduzida em todos os casos, em especial na Braskem, que teve a maior queda de 50,60\%.

Em relação ao grau de endividamento financeiro, houve uma queda drástica no período delimitado do estudo, de $41,15 \%$, indicando que houve uma melhora do perfil da dívida total em relação ao ativo total dos três casos estudados. Mais uma vez a maior queda veio da Braskem, uma queda relevante de 54,73\%.

Finalmente, em relação a participação de capital de terceiros em relação ao capital próprio, houve uma queda geral do índice, puxado principalmente pela fusão do Itaú Unibanco e da BRF. Em relação a Braskem, esse índice obteve um aumento, isso se deu pelo fato da empresa adquirir o passivo a longo prazo alavancado da Quattor, que somado ao seu, aumentou o valor excedente em relação ao seu patrimônio líquido.

Os índices de endividamento dos três casos, obteve uma forte queda após o processo de fusão ou de aquisição, constatando que houve uma melhor geral no perfil da dívida dos grupos formados. 
Tabela 5 - Índices de Rentabilidade

\begin{tabular}{|c|c|c|c|c|c|c|c|c|c|c|c|c|}
\hline \multicolumn{13}{|c|}{ ÍNDICES DE RENTABILIDADE } \\
\hline \multirow{2}{*}{ ÍNDICE } & \multirow{2}{*}{ EMPRESA } & \multicolumn{8}{|c|}{ ANOS RELATIVOS } & \multicolumn{2}{|c|}{ MÉDIA } & \multirow{2}{*}{ VARIAÇÃO } \\
\hline & & 2007 & 2008 & 2009 & 2010 & 2011 & 2012 & 2013 & 2014 & ANTES & DEPOIS & \\
\hline \multirow{3}{*}{$\begin{array}{l}\text { ROA } \\
(\mathrm{Em} \%)\end{array}$} & Braskem & $3 \%$ & $-11 \%$ & $2 \%$ & $5 \%$ & $-1 \%$ & $-2 \%$ & $1 \%$ & - & $-2 \%$ & $-1 \%$ & $67,09 \%$ \\
\hline & BRF & - & $1 \%$ & $1 \%$ & $3 \%$ & $5 \%$ & $3 \%$ & $3 \%$ & $6 \%$ & $2 \%$ & $4 \%$ & $115,88 \%$ \\
\hline & Itaú Unibanco & $1 \%$ & $0 \%$ & $2 \%$ & $2 \%$ & $2 \%$ & $1 \%$ & $2 \%$ & - & $1 \%$ & $2 \%$ & $57,24 \%$ \\
\hline \multicolumn{2}{|c|}{ MÉDIA GERAL } & $2 \%$ & $-3 \%$ & $2 \%$ & $3 \%$ & $2 \%$ & $1 \%$ & $2 \%$ & $6 \%$ & $0 \%$ & $2 \%$ & $702,80 \%$ \\
\hline \multirow{3}{*}{$\begin{array}{l}\mathrm{ROE} \\
(\mathrm{Em} \%)\end{array}$} & Braskem & $11 \%$ & $-68 \%$ & $8 \%$ & $18 \%$ & $-5 \%$ & $-9 \%$ & $7 \%$ & - & $-16 \%$ & $-2 \%$ & $85,27 \%$ \\
\hline & BRF & - & $4 \%$ & $3 \%$ & $6 \%$ & $11 \%$ & $5 \%$ & $7 \%$ & $14 \%$ & $4 \%$ & $9 \%$ & $115,14 \%$ \\
\hline & Itaú Unibanco & $16 \%$ & $7 \%$ & $19 \%$ & $21 \%$ & $20 \%$ & $18 \%$ & $21 \%$ & - & $14 \%$ & $20 \%$ & $42,68 \%$ \\
\hline \multicolumn{2}{|c|}{ MÉDIA GERAL } & $13 \%$ & $-19 \%$ & $10 \%$ & $15 \%$ & $9 \%$ & $5 \%$ & $12 \%$ & $14 \%$ & $0 \%$ & $9 \%$ & $1670,81 \%$ \\
\hline \multirow{3}{*}{ LPA } & Braskem & 1,43 & $-4,94$ & 0,77 & 2,65 & $-0,69$ & $-1,30$ & 0,64 & - & $-0,91$ & $-0,45$ & $50,72 \%$ \\
\hline & BRF & - & 0,26 & 0,28 & 0,93 & 1,59 & 0,92 & 1,17 & 2,46 & 0,49 & 1,52 & $209,52 \%$ \\
\hline & Itaú Unibanco & 8,70 & 3,89 & 2,32 & 2,87 & 3,23 & 3,01 & 3,16 & - & 4,97 & 3,13 & $-36,96 \%$ \\
\hline \multicolumn{2}{|c|}{ MÉDIA GERAL } & 5,06 & $-0,26$ & 1,12 & 2,15 & 1,38 & 0,88 & 1,66 & 2,46 & 1,52 & 1,40 & $-7,63 \%$ \\
\hline
\end{tabular}

Fonte: Elaborada pelo autor

O retorno sobre os ativos obteve uma melhora significativa, sendo puxado positivamente pela variação da BRF e do Itaú Unibanco, de 115,8\% e 57,24\% respectivamente. A Braskem obteve um resultado negativo, pois obteve prejuízo nos primeiros dois anos da aquisição para estruturar suas operações, apenas revertendo esse prejuízo no terceiro ano. Apesar dos resultados negativos da Braskem, a média geral do índice foi positivo em 702,80\%.

O caso é praticamente idêntico no caso do ROE, onde a média geral da variação dos índices foi positiva em 1670,81\%, puxado pela variação positiva dos casos de fusão, de 115,14\% (BRF) e 42,68\% (Itaú Unibanco). Mais uma vez a Braskem foi impactada negativamente nesse índice pelos dois primeiros de prejuízo após a aquisição da Quattor em 2010, gerando uma variação negativa de $85,27 \%$.

Já o lucro por ação obteve uma queda no caso da Braskem e no do Itaú Unibanco. No primeiro caso, a empresa obteve prejuízo líquido nos primeiros dois anos, o que impactou negativamente a distribuição de lucros por ação. No caso do Itaú Unibanco, com houve uma fusão, a empresa decidiu reestrutura sua distribuição de lucros por ação para baixo, resultando numa queda 36,96\%. O caso ocorreu com a BRF, só que no sentido oposto, onde o grupo decidiu 
aumentar seu lucro por ação aos acionistas, ocasionando um aumento de $209,52 \%$.

Pode-se constatar que os resultados se mostraram positivos após o processo de fusão e um pouco mais conturbados no processo de aquisição, onde a empresa adquirente herda todo passivo e o resultado negativo da empresa adquirente, impactando a linha de baixo de sua DRE.

Tabela 6 - Índices de Margem

\begin{tabular}{|c|c|c|c|c|c|c|c|c|c|c|c|c|}
\hline \multicolumn{13}{|c|}{ ÍNDICES DE MARGEM } \\
\hline \multirow{2}{*}{ ÍNDICE } & \multirow{2}{*}{ EMPRESA } & \multicolumn{8}{|c|}{ ANOS RELATIVOS } & \multicolumn{2}{|c|}{ MÉDIA } & \multirow{2}{*}{ VARIAÇÃO } \\
\hline & & 2007 & 2008 & 2009 & 2010 & 2011 & 2012 & 2013 & 2014 & ANTES & DEPOIS & \\
\hline \multirow{3}{*}{$\begin{array}{l}\text { MB } \\
(\mathrm{Em} \%)\end{array}$} & Braskem & $18 \%$ & $16 \%$ & $16 \%$ & $16 \%$ & $11 \%$ & $9 \%$ & $13 \%$ & - & $16,72 \%$ & $11,06 \%$ & $-33,83 \%$ \\
\hline & BRF & - & $24 \%$ & $20 \%$ & $25 \%$ & $26 \%$ & $23 \%$ & $25 \%$ & $29 \%$ & $23,23 \%$ & $25,57 \%$ & $10,04 \%$ \\
\hline & Itaú Unibanco & $28 \%$ & $-101 \%$ & $42 \%$ & $44 \%$ & $32 \%$ & $31 \%$ & $34 \%$ & - & $-10,76 \%$ & $32,38 \%$ & $400,90 \%$ \\
\hline \multicolumn{2}{|c|}{ MÉDIA GERAL } & $23 \%$ & $-21 \%$ & $26 \%$ & $28 \%$ & $23 \%$ & $21 \%$ & $24 \%$ & $29 \%$ & $9,73 \%$ & $23,00 \%$ & $136,38 \%$ \\
\hline \multirow{3}{*}{$\begin{array}{l}\mathrm{ML} \\
(\mathrm{Em} \%)\end{array}$} & Braskem & $3 \%$ & $-14 \%$ & $2 \%$ & $7 \%$ & $-2 \%$ & $-3 \%$ & $1 \%$ & - & $-2,88 \%$ & $-1,06 \%$ & $63,13 \%$ \\
\hline & BRF & - & $1 \%$ & $2 \%$ & $4 \%$ & $6 \%$ & $3 \%$ & $4 \%$ & $8 \%$ & $2,19 \%$ & $4,63 \%$ & $111,89 \%$ \\
\hline & Itaú Unibanco & $16 \%$ & $3 \%$ & $13 \%$ & $17 \%$ & $14 \%$ & $14 \%$ & $17 \%$ & - & $10,79 \%$ & $14,92 \%$ & $38,23 \%$ \\
\hline \multicolumn{2}{|c|}{ MÉDIA GERAL } & $10 \%$ & $-3 \%$ & $6 \%$ & $9 \%$ & $6 \%$ & $4 \%$ & $7 \%$ & $8 \%$ & $3,37 \%$ & $6,16 \%$ & $83,14 \%$ \\
\hline \multirow{3}{*}{$\begin{array}{l}\text { DAG } \\
(\mathrm{Em} \%)\end{array}$} & Braskem & $4 \%$ & $4 \%$ & $4 \%$ & $4 \%$ & $3 \%$ & $3 \%$ & $3 \%$ & - & $3,84 \%$ & $2,77 \%$ & $-27,80 \%$ \\
\hline & BRF & - & $2 \%$ & $2 \%$ & $1 \%$ & $2 \%$ & $1 \%$ & $2 \%$ & $1 \%$ & $1,79 \%$ & $1,42 \%$ & $-20,82 \%$ \\
\hline & Itaú Unibanco & $5 \%$ & $3 \%$ & $15 \%$ & $17 \%$ & $14 \%$ & $14 \%$ & $16 \%$ & - & $7,76 \%$ & $14,73 \%$ & $89,78 \%$ \\
\hline \multicolumn{2}{|c|}{ MÉDIA GERAL } & $5 \%$ & $3 \%$ & $7 \%$ & $8 \%$ & $6 \%$ & $6 \%$ & $7 \%$ & $1 \%$ & $4,46 \%$ & $6,31 \%$ & $41,29 \%$ \\
\hline
\end{tabular}

Fonte: Elaborada pelo autor

A margem bruta da BRF e do Itaú Unibanco apontaram uma variação positiva de 10,04\% e 400,90\%. Já a Braskem, teve uma queda em sua MB de 33,83\%. Como a média geral positiva, pode-se concluir que as empresas analisadas apresentaram uma maior eficiência no controle e gestão da sua estrutura de custos.

Considerando a margem líquida, o caso se repete. As margens da BRF e do Itaú Unibanco apontaram uma variação positiva de 11,89\% e 38,23\% respectivamente. No caso da Braskem, a margem líquida encontra-se em queda de $63,13 \%$ devido ao fato de que a empresa teve prejuízo líquido nos dois primeiros anos após a aquisição da Quattor, apenas revertendo no terceiro. Entretanto, em geral, houve uma alta de $83,14 \%$ em relação ao índice. 
Finalmente, no que se refere as despesas gerais e administrativas, pode-se concluir que de uma maneira geral houve uma melhora, apesar do resultado negativo do Itaú Unibanco, que obteve maiores despesas por conta do grande processo de fusão em que a empresa concluiu, que, por conta de obrigações sindicais, o banco teria que manter por pelo menos dois anos todos os empregados vindos do Unibanco, aumento dessa maneira suas despesas. No caso da Braskem e da BRF a empresa demonstrou uma melhora na eficiência de controle de suas despesas administrativas, em proporção às suas receitas líquidas, com uma queda de 27,89\% e 20,82\% dos índices respectivamente.

Em termos gerais as empresas que passaram por processos de fusões foram mais eficientes no que se refere os índices de margens financeiras. A Braskem que passou por um processo de aquisição sofreu nos primeiros dois anos, mas conseguiu reverter os resultados ruins a partir do terceiro ano.

\section{Conclusão}

Esse estudo teve como objetivo realizar uma análise dos processos de fusão e aquisição que ocorreram entre os anos de 2010 e 2011 de três empresas em diferentes setores do mercado brasileiro, através de índices financeiros para determinar se o desempenho econômico-financeiro foi melhor ou pior com $o$ processo.

O estudo foi desenvolvido por meio da comparação dos valores médios de índices no triênio anterior e no posterior à união das empresas. As empresas escolhidas foram a Braskem (aquisição), BRF (fusão) e Itaú Unibanco (fusão).

Identificou-se que houve uma melhora nos índices de liquidez dos três casos em geral. Na média geral, os índices tiveram uma média positiva de 2,04\%. No que se refere a curto prazo (LC), a liquidez da Braskem e do Itaú Unibanco foram favorecidas, com recursos suficientes para quitar por completo sua dívida de CP. Em relação aos índices de liquidez geral, a empresa que passou por processo de aquisição obteve resultado negativo, especialmente por herdar uma alta dívida de longo prazo (oriunda dos investimentos pesados do setor) vinda da Quattor. Nas demais empresas os resultados foram positivos, indicando a forte capacidade de ambas de liquidar suas dívidas com seus credores. 
No que se refere ao nível de endividamento, houve uma melhor geral, onde as três empresas mostraram-se eficientes na redução de sua dívida de CP. A média geral foi da redução do nível de endividamento de $25,44 \%$. No que tange as dívidas de CP todas as empresas obtiveram sucesso na redução após o processo de aquisição ou de fusão. Nas dívidas totais em relação ao capital próprio dos grupos houve uma melhora para as empresas que passaram pelo processo de fusão. No caso da Braskem, que passou por um processo de aquisição, ela obteve o passivo por completo da concorrente Quattor, onde as dívidas de LP estavam robustas (dado o forte investimento de LP que o setor exige), aumento assim a relação da dívida total com o PL.

Em relação aos índices de rentabilidade, pode-se afirmar que nos casos de fusão todos os índices obtiveram uma melhora significativa, principalmente no ROA e no ROE. Já em relação a empresa que passou pelo processo de aquisição, houve uma pior nos índices nos dois primeiros anos após a composição da empresa, visto que a empresa sofreu com prejuízos líquidos no fim de cada ano contábil (dado ao enfraquecimento do setor naquela época, resultando em uma recita menor e a reestruturação da empresa em relação a aquisição, resultando em maiores custos). Em termos práticos, a média geral dos índices de rentabilidade foi positivo em $788,66 \%$, evidenciando que a situação econômica das empresas melhorou após a combinação.

Finalmente, nas margens, conclui-se que houve uma melhora geral nas margens brutas e líquidas das empresas que passaram por processos de fusão (Itaú Unibanco e BRF), apresentando uma maior eficiência no controle e gestão da sua estrutura de custos. No caso da Braskem, a empresa sofreu em seus dois primeiros anos com receitas menores e com prejuízo líquido. Em relação as despesas administrativas gerais, houve apensa um aumento no processo de fusão do Itaú com o Unibanco, devido principalmente com o grande porte da operação e por questões sindicais significativas. Em termos gerais as empresas que passaram por processos de fusões foram mais eficientes no que se refere os índices de margens financeiras. A Braskem que passou por um processo de aquisição sofreu nos primeiros dois anos, mas conseguiu reverter os resultados ruins a partir do terceiro ano. A média geral foi positiva em $86,93 \%$.

Os resultados concordam com aqueles realizados por Camargos e Barbosa em 2005, que houve uma melhora na situação econômica das empresas 
estudadas gerando melhoras nas sinergias operacionais e gerenciais. Entretanto, um ponto pode ser considerado diferente do trabalho desses autores, onde há uma melhora nos três casos da situação financeira após o processo de aquisição e/ou fusão, mostrando a capacidade maior de liquidez. Outro ponto importante a ser destacado, é a diferença dos índices financeiros de um processo de fusão com o de aquisição, onde há uma melhora mais aparente e rápida após o processo de fusão a frente de um processo de aquisição. Isso se deve principalmente ao fato de que no processo de aquisição a empresa adquirente herda todo o passivo e o resultado de uma outra companhia, o que por muitas vezes tem que a estrutura todas as dívidas, capital próprio, custos e resultados a gestão da incorporadora, o que leva mais tempo.

Além disso é válido comentar que os resultados encontrados não podem ser generalizados ao mercado como um todo, visto que esta pesquisa contempla uma pequena amostra do universo de F\&As que ocorreram no período, mas são um bom sinalizador das consequências de tais processos no mercado brasileiro, em razão da falta de pesquisas sobre o tema. Além disso, os resultados diferem de setor para setor, que na época foram afetados pela situação estável da economia nacional, impactando de forma visível nos resultados apresentados.

\section{Referencial Bibliográfico}

ASSAF NETO, Alexandre. Estrutura e análise de balanços. São Paulo: Atlas, $2015-615 p$.

BACEN, Banco Central do Brasil. Disponível em: <http://www.bcb.gov.br/pec/Indeco/Port/indeco.asp>. Acesso em: 30 out. 2016.

BRASKEM, Braskem S.A. - Disponível em: <http://www.braskemri.com.br/relatorios-anuais>. Acesso em: 08 nov. 2016 
BRF, Brasil Foods S.A. Disponível em: < http://ri.brfglobal.com/conteudo_pt.asp?idioma $=0 \&$ tipo $=52159 \&$ conta $=28 \& i d=196342>$. Acesso em 08 nov. 2016.

BREALEY, Richard A.; MYERS, Stewart C.; ALLEN, Franklin. Princípios de finanças corporativas. AMGH Editora, 2013.

CADE, Conselho Administrativo de Defesa Econômica. Disponível em:<http://www.cade.gov.br>. Acesso em: 30 out. 2016.

CAMARGOS, Marcos Antônio; BARBOSA, Francisco Vidal. Análise do desempenho econômico-financeiro e da criação de sinergias em processos de fusões e aquisições do mercado brasileiro ocorridos entre 1995 e 1999. REGE Revista de Gestão, v. 12, n. 2, p. 99-115, 2005.

CAMPOS, Marielly. Entenda por que acontecem processos de fusões e aquisições. Julho de 2011 Disponível em: http://noticias.band.uol.com.br/. Acesso em 25 set. 2016.

EXAME, Editora Abril. Disponível em: <http://exame.abril.com.br/negocios/asdez-maiores-fusoes-e-aquisicoes-de-2010/\#4>. Acesso em 25 set. 2016.

ITAÚ UNIBANCO, Itaú Unibanco Holdings S.A. Disponível em: $<$ https://www.itau.com.br/relacoes-com-investidores/informacoes-financeiras>. Acesso em 08 nov. 2016

MEDEIROS, Renata. www.artigos.com/administracao. Postado em 27/04/2009. 
SANTOS, Marlos Henrique dos et al. O panorama das fusões e aquisições no mundo e na economia brasileira a partir da década de 90. 2007.

SANVICENTE, Antônio Zoratto. Administração financeira. Pioneira, 1978. Sao Paulo: Atlas, 1978.

TRICHES, Divanildo. Fusões, aquisições e outras formas de associação entre firmas no Brasil. Revista de Administração, São Paulo, v. 31, n. 1, p. 14-31, jan.mar. 1996. 